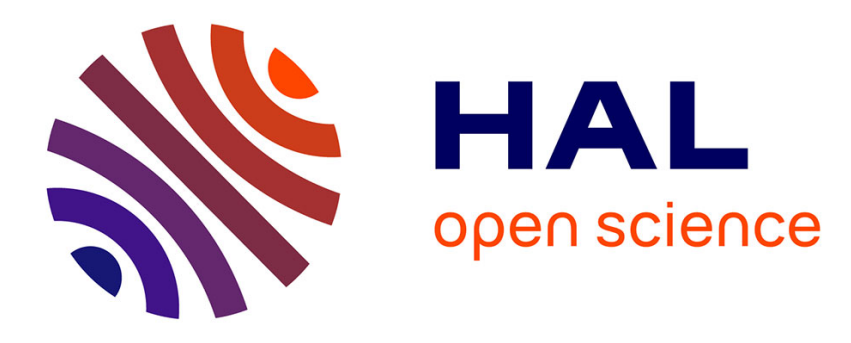

\title{
How to Knock Out Feedback Circuits in Gene Networks?
}

\author{
H Gruber, A Richard, C Soulé
}

\section{To cite this version:}

H Gruber, A Richard, C Soulé. How to Knock Out Feedback Circuits in Gene Networks?. Pattern Formation in Morphogenesis - Problems and Mathematical Issues, 2013, 978-3-642-20164-6. hal01298860

\section{HAL Id: hal-01298860 https://hal.science/hal-01298860}

Submitted on 6 Apr 2016

HAL is a multi-disciplinary open access archive for the deposit and dissemination of scientific research documents, whether they are published or not. The documents may come from teaching and research institutions in France or abroad, or from public or private research centers.
L'archive ouverte pluridisciplinaire HAL, est destinée au dépôt et à la diffusion de documents scientifiques de niveau recherche, publiés ou non, émanant des établissements d'enseignement et de recherche français ou étrangers, des laboratoires publics ou privés. 


\title{
How to knock out feedback circuits in gene networks?
}

\author{
H. GRUBer ${ }^{*}$ A. Richard ${ }^{\dagger}$ C. SoulÉ ${ }^{\ddagger}$
}

The development of living organisms involve the successive activation of several gene networks. It is often known if activation or inhibition of a given gene occurs in these networks, but their global dynamic remains poorly understood. It is thus important to understand the function of motives contained in such a network, and for this one has to be able to perform knock out experiments.

The role of feedback circuits for the dynamic of gene networks is by now well established, both experimentally and theoretically. We shall discuss the possibility of knocking out these circuits.

To a gene network $N$ is associated an interaction graph $G$, defined as follows: the vertices of $G$ are the genes of $N$; there is a positive edge

$$
A \longrightarrow B
$$

in $G$ when (the product of) the gene $A$ activates the expression of $B$; and there is a negative edge

$$
A \longrightarrow B
$$

when the gene $A$ inhibits the expression of $B$. Given an oriented circuit $C$ in $G$, we say that $C$ is positive (resp. negative) when it contains an even (resp. an odd) number of negative edges.

R. Thomas conjectured that, if $N$ has several stationary states (i.e. if $N$ leads to differentiation), the associated graph $G$ must contain a positive circuit; and, if $N$ presents sustained oscillations, the graph $G$ must contain a negative circuit of length at least two. Both Thomas rules were proved mathematically, for discrete and differential models of $N$ (see [3], [4] and references therein).

In view of these results, it may be of interest to knock out some of the genes in $N$, in order to obtain a new network $N^{\prime}$, the graph of which contains only few circuits. For instance, if $I$ is a set of genes such that $G \backslash I$ has no circuits,

\footnotetext{
*email: info@hermann-gruber.com - address: knowledgepark AG, Leonrodstr. 68, D-80636 München, Germany

†email: richard@unice.fr - address: I3S, 2000 routes des Lucioles, Les Algorithmes - Euclide B, 06903 Sophia Antipolis, France

‡email: soule@ihes.fr - address: IHÉS, 35 route de Chartres, 91440 Bures-sur-Yvette, France
} 
then knocking out all the genes in $I$ will lead to a new network $N^{\prime}$ such that its interaction graph $G^{\prime}$ does not contain any circuit (since it is a subgraph of $G \backslash I)$. The dynamic of $N^{\prime}$ has then to be very simple: it has to evolve towards a unique stationary state (this result is due to Robert [5] for discrete dynamical systems, and it holds for differential models with decay, as those treated in [6]). If this does not happen, one has to conclude that $N$ does not provide a complete description of the system under study: new genes and/or new interactions have to be searched for.

Since the network $N$ can contain many circuits (up to hundreds), it is of interest to find a good algorithm for knocking out all circuits in a graph $G$ by deleting a minimal amount of vertices. This is a purely combinatorial problem, which is known to be NP-complete [2].

Recently, one of us (H.G.) found a fairly simple algorithm which, given $G$, gets rid of all circuits in $G$ by deleting "few" vertices. This algorithm is the following. Given a vertex $v$ in $G$, let $N(v)$ be the set of vertices $w$ in $G, w \neq v$, such that $v w$ is an edge, and let $d(G, v)$ be the number of vertices in $N(v)$. One defines as follows a finite sequence of subgraphs $G_{n}$ in $G$. Given $G_{n}$, we let $v_{n} \in G_{n}$ be a vertex such that $d\left(G_{n}, v_{n}\right)$ is minimal. Then $G_{n+1}$ is the graph spanned by $G_{n}-\left(N\left(v_{n}\right) \cup\left\{v_{n}\right\}\right)$. The definition of $G_{n}$ stops when there is no vertex left. Now, consider the subgraph $H$ in $G$ spanned by the vertices $v_{1}, v_{2}, \ldots, v_{n}, \ldots$ It can be shown [1] that $H$ does not contain any oriented circuit, and that its set of vertices has order at least

$$
\sum_{v \text { vertex in } G} \frac{1}{1+d(G, v)} .
$$

It would be interesting to apply this algorithm to actual gene networks. When edges in $G$ are endowed with a sign, one would also like to have an efficient algorithm for depriving $G$ of its positive (resp. its negative) circuits, by knocking out a small set of vertices. We plan to address these questions elsewhere.

\section{References}

[1] H. Gruber, Bounding the feedback vertex number of digraphs in terms of vertex degrees, Discrete Applied Mathematics, 2011. In press.

[2] R. M. Karp. Reducibility among combinatorial problems, in: R. E. Miller and J. W. Thatcher (eds.), Complexity of Computer Computations. New York: Plenum (1972) 85-103.

[3] M. Kaufman, C. Soulé, R. Thomas, A new necessary condition on interaction graphs for multistationarity, Journal of Theoretical Biology 248 (2007) 675-685. 
[4] A. Richard, Negative circuits and sustained oscillations in asynchronous automata networks, Advances in Applied Mathematics 44 (2010) 378-392.

[5] F. Robert, Discrete iterations: a metric study, in: Series in Computational Mathematics, Vol. 6, Springer-Verlag, Berlin-Heidelber-New York (1986).

[6] C. Soulé, Mathematical approaches to differentiation and gene regulation, C.R. Paris Biologies 329 (2006) 13-20. 